\title{
The analysis of drag reduction in Kuwaiti crude oil samples using surfactants and polyacrylamide
}

\author{
Hamad Al-Adwani ${ }^{1} \cdot$ Adam Al-Mulla $^{1}$ \\ Received: 6 May 2018 / Accepted: 23 November 2018 / Published online: 28 January 2019 \\ (c) The Author(s) 2019
}

\begin{abstract}
The rheological characteristics of Kuwait crude oil samples were studied as a function of the American Petroleum Institute gravity (API), drag reduction material and concentration, isothermal and nonisothermal conditions, and mixer speed and frequency. Accurate measurements and analyses of rheological characteristics are important to determine the effect of a drag reduction agent and ambient conditions on the crude oil flow characteristics and required pumping power. Three crude oil samples obtained from different wells with API values of 14.81 (crude A), 16.33 (crude B) and 14.09 (crude C) were used in the experiments. Various polyacrylamide (PAM) concentrations were used to assess the effect on the rheological properties of the three crude oil samples. The disruption of wax crystal formation and the changes in loss modulus $\left(G^{\prime \prime}\right)$, viscosity and strain were measured under isothermal and nonisothermal conditions. The PAM performance was compared with that of five surfactants, namely poly(sodium 4-styrenesulfonate) (PSSS), sodium dodecyl sulfate (SDS), cetyltrimethylammonium bromide (CTAB), hexadecylphosphocholine (HTPC), and CHP, which is an equal molar ratio mixture of PSSS, CTAB and HTPC. For a surfactant concentration of $70 \mathrm{ppm}$, PSSS results in the lowest viscosity value for crude A, while CHP results in the lowest viscosity value for crude B. An increase in the loss modulus $\left(G^{\prime \prime}\right)$ values was obtained with the addition of PSSS or CHP.
\end{abstract}

Keywords Kuwaiti crude oil $\cdot$ Rheology $\cdot$ Agglomeration $\cdot$ Emulsions $\cdot$ Surfactants $\cdot$ Polyacrylamide

\section{Introduction}

Wax in crude oil creates major technical difficulties in oil industry pipelines and storage tanks, especially in the regions that reach temperatures below $5{ }^{\circ} \mathrm{C}$. Crude oil behaves as a viscoelastic material at pour point temperatures. Below the cloud point, wax deposits can form along the walls of pipes, causing flow loss. When crude oil is at temperatures below the pour point, gelation occurs, causing severe pipeline clogs and inefficient pumping. To break down the gels and restart the pumping process, pipelines need to be pressurized. In rheological terms, the process of restarting the production cycle by destroying the gel is related to the oil yield behavior. Several researchers, including Wardhaugh and Boger (1991a, b), Ronningsen (1992),

Hamad Al-Adwani

dr.aladwani@gmail.com

1 Chemical Engineering Department, College of Engineering and Petroleum, Kuwait University, P.O. Box 5969, 13060 Safat, Kuwait
Chang et al. (1998), and Chang et al. (1999), have studied the yield point for gel formation in crude oils and reported the rheological data. A later study by Singh et al. (2004) indicated that at temperatures between the pour point and the cloud point, the wax crystals develop a gel-like structure with properties similar to those of the gels that form below the pour point. The literature indicates that a relationship exists between the flow properties and the shear history of crude oil. At temperatures above the wax attainment temperature (WAT), crude oil exhibits Newtonian characteristics, while below the WAT, oils become gels (Ronningsen 1992). After being subjected to an external force, crude oil begins to flow, and with simultaneous cooling, the oil shows viscoelastic characteristics that are generally observed at or below the WAT (Ronningsen 1992). A few important literature observations related to waxy crude oil are as follows.

- Rheological studies on a crude oil sample at rest can be used to determine the yield point, which is useful for applications that involve pumping gelled crude oils (Rafael et al. 2015). 
- A relationship between the applied shear force and the cooling behavior was reported by Wardhaugh and Boger (1991a). At an isothermal temperature, the rheological properties depend on the thermal history of the oil, i.e., the number of stress applications during pumping and the applied shear rate. With an increase in shear stress and a constant shear rate and temperature during the cooling stage, the stress experienced by crude oil decreases and plateaus after a few hours based on the cooling rate. At shear rates lower than $1 \mathrm{~s}^{-1}$, crude oils form a gel.

- Wardhaugh and Boger (1991b) observed that the properties of the sheared crude oils left undisturbed overnight at an isothermal temperature do not change. The crystalline structure recovery at isothermal temperatures of North Sea crude oil has been attributed to the irreversible breakage of the 'weak' bonds in the chemical structures present in the crude oil (Ronningsen 1992). No characterization details pertaining to the breakage of weak and strong bonds have been reported. The relationships among the microstructure, viscosity, yield stress and storage modulus $\left(G^{\prime}\right)$ values have not been reported thus far. The micrographs published by Russell and Chapman (1971) relate the crystal size to the shear rate.

Drag-reducing agents (DRAs) have been extensively and effectively used for transport operations in various industries, such as petroleum, sewage, irrigation, marine, and firefighting (Singh 2004; Morgan and McCormick 1990; Ptasinski et al. 2001; Gad-el-Hak 2006). DRAs play a pivotal role in the petrochemical industry and aid the efficient transport of liquid fossil fuels from both newly discovered and semidepleted natural reservoirs. Polymer solutions are more effective for reducing drag in crude oils than other nonpolymeric additives. Literature reports cite up to $80 \%$ reduction in drag in crude oil upon the addition of a polymer DRA solution at concentrations less than 100 ppm (Hassanean et al. 2016; Albusairi and Al-Mulla 2017).

Surfactants have been effectively used as DRAs due to their ability to form defined structures known as micelles. Micelles can spontaneously orient themselves at an interface to reduce the interfacial tension between immiscible phases and promote mixing (Myers 2006).

Surfactants are classified as cationic, anionic or zwitterionic (amphoteric). One of the most important characteristics of a surfactant that aid its performance as a DRA is its ability to 'heal'. Due to this characteristic, a surfactant that experiences degradation under high shear can realign its molecules and return to its initial state in a matter of seconds (AbdulHadi and Khadom 2013; Mowla and Naderi 2006). The selfhealing ability of a surfactant after induced shear differentiates it from other DRAs, such as aluminum di-soaps, which disintegrate under high shear and do not self-heal, making them unsuitable for petroleum product transport operations (Hadri and Guillou 2010).

The viscoelastic behavior of polymeric surfactants plays an important role in mitigating the drag effects in crude oil. Surfactant solutions have shown Newtonian behavior at concentrations of less than $50 \mathrm{ppm}$. The literature indicates that the extensional viscometric effect of these surfactants may influence their drag-reducing ability (Zirnsak et al. 1999; Toonder et al. 1997; Stelter and Brenn 2000; Wunderlich et al. 2000).

The following is a summary of many rheological studies on waxy crude oils in the presence of polymeric and surfactant DRAs. Popoola et al. (2015) studied the effect of triethanolamine (TEA) as a flow improver additive on NigerDelta crude oil and investigated the rheological properties of the crude oil under nonisothermal conditions. They noted that the flow properties of the crude oil were influenced by the resins and asphaltenes present in the oil. They concluded that TEA is an effective flow improver additive for NigerDelta crude oil and temperature variations have a direct effect on the crude oil viscosity.

Soni and Bharambe (2006) synthesized copolymers of maleic anhydride and alkyl alcohol esters with oleic acid and methacrylic acid, and studied their effects on crude oil from the Gandhar oil field, India. High concentrations of the synthesized polymeric additives (100, 500 and $1000 \mathrm{ppm})$ were added to the crude oil, and the viscoelastic reduction mechanism was studied. They concluded that the synthesized additives acted as flow improver additives and enhanced the pour point depression.

Pedersen et al. (1991) identified a relationship between the cooling rate and the amount of crystals formed at different temperatures for 17 types of North Sea crude oil. Dirand et al. (1988) reported the formation of needle-type crystals upon the slow cooling of a wax-oil gel and identified the structures of the crystals after evaluating their morphology. Singh et al. (1999) used food-grade wax (Mobil M140) with mineral oil (Blassdol) and kerosene in a ratio of $3: 1$, and studied the effect of the cooling rate on the morphology of the formed crystals. They also performed dynamic rheological studies on a model crude oil containing varying amounts of dissolved wax at a constant shear stress. Using dynamic measurements, a correlation was found among the gelation temperature, wax content and cooling rate. A phase diagram was produced to relate the wax content to the temperature for different model mixtures, and a model wax and oil system was used to study the gelation process in the mixtures. The wax-oil mixtures separate into two layers with different characteristics when the mixtures are sheared at a low cooling rate or a high steady shear stress. A depression in the gelation point of the wax-oil mixture was noted with a decrease 
in cooling rate or an increase in steady shear stress. The wax-oil phase diagram depended on the shear and thermal history of the mixture.

A commercial high-molecular weight poly-alpha-olefin was used as a DRA at a concentration of $60 \mathrm{ppm}$ to improve the pressure drop in pipelines carrying waxy crude oil (Hassanean et al. 2016). The results showed that an increase in DRA concentration resulted in an increase in viscosity at temperatures below $80{ }^{\circ} \mathrm{F}$. No correlation was detected between the DRA concentration and the viscosity at temperatures above $80^{\circ} \mathrm{F}$.

PAM, a nonionic surfactant without a charged head group, is commonly used as a drag-reducing surfactant. Anionic surfactants precipitate in the presence of calcium and magnesium ions to form the corresponding salts (Zakin et al. 1998). Cationic surfactants are not easily biodegradable, but they do have excellent drag-reducing properties over a wide temperature range, in contrast to anionic surfactants (Bewersdorff and Ohlendorf 1988). Zwitterionic surfactants have both positive and negative charges on the same molecule and are sensitive to the presence of other ions, which can reduce their stability. Zwitterionic surfactants are biodegradable and less toxic than anionic and cationic surfactants. Combinations of zwitterionic surfactants with an anionic ether-containing surfactant as DRAs have been reported in the literature (Hellsten and Harwigsson 1996). The combination of a betaine zwitterionic surfactant with an anionic sulfonate or sulfate surfactant to form a new DRA has been reported. These surfactant combinations have biodegradable properties, and can tolerate water and electrolytes over a temperature range of $50-120^{\circ} \mathrm{C}$. Quaternary ammoniumtype cationic surfactants have been used in the presence of counterionic compounds such as n-alkyl-trimethyl-ammonium-3-hydroxy-2-naphthoate (Usui and Saeki 1993). The addition of a cationic surfactant is effective for reducing the drag and the heat transfer in turbulent flow I pipes for commercial heating and cooling plants using water as a medium.

Mozaffari et al. (2015) studied the relation between asphaltene agglomeration and the viscosity of diluted bitumen with an objective of improving the heavy oil extraction. In this study, it is reported that the onset of asphaltene precipitation in heptanes and heptol continually decreased on aging for a period of 30 days. The decrease in viscosity was attributed to the formation of asphaltene agglomerates, which precipitated, decreasing the asphaltene content in the mixture.

The rheology of different pure liquids and bitumen diluted in heptol was studied using the capillary driven flow method to gain an insight into the flow of crude oil in nanoporous media (Mozaffari et al. 2017). Theoretical models for the capillary filling of Bingham plastic fluids were developed to probe the non-Newtonian behavior of diluted bitumen before asphaltene precipitation. The Bingham plastic model was found to better describe the rheology at the nanoscale level than the Newtonian model.

Kane et al. (2004) studied the relation between the rheological properties and the structure of waxy crude oil under flow and quiescent conditions. The amount of crystalline materials that formed as a function of temperature was measured using a differential scanning calorimeter, and the morphology was studied using a transmission electron microscope (TEM). The rheological changes that occur in the structure of the paraffin that forms upon crystallization have been ascribed to the morphology of the clusters that form due to wax aggregation. The wax agglomeration observed in the rheological measurements agrees with the TEM observations.

Albusairi and Almulla (2017) investigated the effect of adding PAM to four different Kuwaiti crude oils under isothermal conditions. Different concentrations (25, 50 and $75 \mathrm{ppm}$ ) were chosen to study the viscoelastic behavior of the raw and treated crude oil samples. They observed that the sulfur amount present in the crude oil had an effect on the viscoelastic behavior of the treated and untreated oil samples. They concluded that $50 \mathrm{ppm}$ of PAA had the best drag-reducing effect for the investigated Kuwaiti crude oil samples.

Al-Roomi et al. (2004) synthesized a novel DRA containing two partial charges, which decreased the immiscible characteristics of the investigated oil emulsion, and studied its effect on heavy Kuwaiti crude oil. Rheological analyses were carried out on oil/aqueous surfactant solution emulsions of the synthesized and commercially available surfactants. They concluded that the newly developed surfactant was more effective than the commercially available surfactants and produced less viscous oil/aqueous surfactant emulsions, which require less energy during the transport processes.

This research studied the effect of using an equimolar mixture of anionic, cationic and zwitterionic surfactants on Kuwaiti crude oil samples with high API values. This approach has not been previously applied to Kuwaiti crude oil. The study determined the relationships between the crystals that form upon cooling and different rheological parameters, such as the viscosity, loss modulus $\left(G^{\prime \prime}\right)$ and agglomerates that form when the oil is cooled to $15^{\circ} \mathrm{C}$. A relationship was also observed for the breakdown of agglomeration in the presence and absence of PAM. Another objective of the present work was to investigate the effect of the surfactant concentration on the viscoelastic properties of Kuwaiti crude oil under nonisothermal conditions.

\section{Materials and methods}

PAM with a molecular weight (MW) of 5,000,000 g/ mol was purchased from Sigma-Aldrich, UK. CTAB (MW $364.46 \mathrm{~g} / \mathrm{mol}$ ), PSSS (MW 1,000,000 g/mol) and

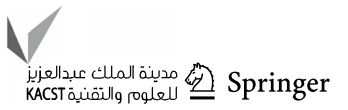


HTPC (MW $364.45 \mathrm{~g} / \mathrm{mol}$ ), the cationic, anionic and zwitterionic surfactants, respectively, with a $99 \%$ purity were purchased from BDH Laboratory, Kuwait. Sodium dodecyl sulfate (SDS) (MW $288 \mathrm{~g} / \mathrm{mol}$ ), a commercially available anionic surfactant, was also purchased from the same supplier. All these surfactants are soluble in water and were subjected to a temperature range of $15-50{ }^{\circ} \mathrm{C}$ in the experimental work. The literature reports that the cationic, anionic, and zwitterionic surfactants and PAM are stable up to temperatures of $180{ }^{\circ} \mathrm{C}$ (Angstadt and Tsao 1987); Handy et al. 1979; Robertson 1957).

Three Kuwaiti crude oil samples from three geographical locations (situated approximately $10 \mathrm{~km}$ apart) with different API values and sulfur contents (as listed in Table 1) were used for this work. A detailed saturate, asphaltene, resin, and aromatic (SARA) analysis is also shown in Table 1. The maximum sulfur content is in crude oil sample B, and its API value is 16.33 . The crude oil with the lowest sulfur content is sample $\mathrm{C}$, and its API value is 14.09 . The SARA analysis was carried out by an Iatroscan TLC-FID analyzer (Bechenheim, Germany) per the literature procedure (Hannisdal et al. 2005). The elemental analysis was carried out using a Vario MACRO Cube analyzer (Langenselbold, Germany) to determine the $\mathrm{C}, \mathrm{H}, \mathrm{N}, \mathrm{S}$ and $\mathrm{O}_{2}$ contents, and the results are given in Table 1.

\section{Emulsion preparation}

The PAM master solution with a concentration of $1000 \mathrm{ppm}$ was prepared in distilled water. Different surfactant solutions with concentrations of 40, 50, 70 and $100 \mathrm{ppm}$ were prepared from the master solution using distilled water. After incorporation of the PAM granules, these solutions were sheared for $5 \mathrm{~h}$ at $5000 \mathrm{rpm}$ and kept overnight at room temperature for complete dissolution. An appropriate volume of the aqueous surfactant solution was added into the crude oil samples at room temperature, and the surfactant solution/crude oil mixture was sheared at $5000 \mathrm{rpm}$ for $5 \mathrm{~h}$ to obtain a homogenous mixture. The prepared samples are designated by the letters A, B, and $\mathrm{C}$, which define the oil type, and the numbers $0,40,50$, 70 and 100, which define the PAM concentration in ppm.

A CHP emulsion containing a 1:1:1 mol ratio of CTAB, HTPC and PSSS was prepared, and its drag-reducing effect on the Kuwaiti crude oil samples was studied. The sample designations include the letters $\mathrm{A}$ and $\mathrm{B}$ to define the oil type, the numbers $40,50,70$, and 100 to define the surfactant concentration, and CTAB, HTPC, PSSS, CHP, and SDS to define the surfactant.
Table 1 Characterization of Kuwaiti crude oil samples A, B and C

\begin{tabular}{|c|c|c|c|}
\hline Sample & A & $\mathrm{B}$ & $\mathrm{C}$ \\
\hline Water content $(\%)$ & 10.5 & 8.2 & 7.6 \\
\hline Sediment content $(\%)$ & 0.1 & 0 & 0.1 \\
\hline Specific gravity @ $15^{\circ} \mathrm{C}$ & 0.9671 & 0.9572 & 0.9719 \\
\hline API gravity @ $15^{\circ} \mathrm{C}$ & 14.81 & 16.33 & 14.09 \\
\hline \multicolumn{4}{|l|}{ Density analysis } \\
\hline Density at $15^{\circ} \mathrm{C}$ & 0.9662 & 0.9562 & 0.9698 \\
\hline Density at $25^{\circ} \mathrm{C}$ & 0.9595 & 0.9493 & 0.9632 \\
\hline Density at $40{ }^{\circ} \mathrm{C}$ & 0.9495 & 0.9394 & 0.9532 \\
\hline \multicolumn{4}{|l|}{ Kinematic viscosity } \\
\hline $\mathrm{mm}^{2} / \mathrm{s}$ (centistokes) at $15^{\circ} \mathrm{C}$ & 1250 & 635.9 & 1628.9 \\
\hline $\mathrm{mm}^{2} / \mathrm{s}$ (centistokes) at $25^{\circ} \mathrm{C}$ & 557.27 & 307.23 & 705.36 \\
\hline $\mathrm{mm}^{2} / \mathrm{s}$ (centistokes) at $40^{\circ} \mathrm{C}$ & 204.81 & 124.08 & 249.86 \\
\hline \multicolumn{4}{|l|}{ Dynamic viscosity } \\
\hline $\mathrm{mPa}$-s (centipoise) at $15^{\circ} \mathrm{C}$ & 1207.7 & 608.03 & 1579.7 \\
\hline $\mathrm{mPa}$-s (centipoise) at $25^{\circ} \mathrm{C}$ & 534.71 & 291.66 & 679.43 \\
\hline $\mathrm{mPa}$-s (centipoise) at $40^{\circ} \mathrm{C}$ & 194.46 & 116.55 & 238.16 \\
\hline \multicolumn{4}{|l|}{ SARA analysis } \\
\hline Asphaltene & 6.53 & 6.3 & 7.05 \\
\hline Resin & 11.17 & 11.2 & 10.94 \\
\hline Aromatics & 67.75 & 68.27 & 68.04 \\
\hline Saturates & 14.55 & 14.23 & 13.97 \\
\hline Total & 100 & 100 & 100 \\
\hline \multicolumn{4}{|l|}{ Molecular weight analysis } \\
\hline Molecular weight $\mathrm{gm} / \mathrm{cc}$ & 344 & 330 & 371 \\
\hline \multicolumn{4}{|l|}{ Elemental analysis } \\
\hline N\% & 0.37 & 0.48 & 0.41 \\
\hline $\mathrm{C} \%$ & 76.31 & 77.77 & 73.62 \\
\hline $\mathrm{H} \%$ & 10.78 & 9.57 & 10.64 \\
\hline $\mathrm{S} \%$ & 5.09 & 5.18 & 4.54 \\
\hline$H / C$ ratio & 0.141 & 0.123 & 0.144 \\
\hline
\end{tabular}

\section{Rheological measurements}

A controlled stress and strain rheometer made by Bohlin Malvern, UK, was used to study the rheology of the Kuwaiti crude oil samples. The effect of the cooling process on the wax crystal structure was studied between $50{ }^{\circ} \mathrm{C}$ and $15^{\circ} \mathrm{C}$ at a rate of $1^{\circ} \mathrm{C} / \mathrm{min}$ for frequencies varying between 0.1 and $1 \mathrm{~Hz}$. Oscillatory measurements were obtained in the oscillatory stress mode to determine the viscous characteristics of the treated and untreated crude oil samples. A plot of $G^{\prime \prime}$ versus the shear stress was created, and a constant stress value in the linear region was chosen at a frequency of $1 \mathrm{~Hz}$. This value was held constant for the oscillatory measurements. Oscillatory measurements were also conducted to study the effect of temperature on the gel formation. The geometry used in this rheological study was a coaxial cup and bob cylinder setup with a diameter of $25 \mathrm{~mm}$. The gap between the spindle and the cuvette of $150 \mu \mathrm{m}$ was constant. 
The middle portion of the linear region, which corresponds to a shear stress of $1 \mathrm{~Pa}$, was chosen and held constant for all further tests to study the viscoelastic properties of the crude oil samples.

\section{Results and discussion}

Table 1 describes the physical characteristics of the Kuwaiti crude oil samples investigated in this work. The densities of the crude oil samples range from 0.9394 to $0.9698 \mathrm{gm} / \mathrm{cm}^{3}$. Crude oil sample $\mathrm{C}$ has higher densities than those of sample A and B at all temperatures. The SARA analysis shows that sample $\mathrm{C}$ has the lowest saturate and resin contents, and the highest asphaltene content. The SARA analysis, which is related to rheological properties such as viscosity, reveals that the sample with the lowest dynamic viscosity (sample B) has the lowest asphaltene content. The analysis also reveals that the asphaltene content in the three crude oil samples is lower than the contents of the resins and saturates, and that sample B has the highest resin content. With decreasing temperature, the resins, waxes, asphaltenes and saturates can potentially agglomerate and affect the rheological properties of the oil. The relationship between the SARA analysis result and the rheological properties will be discussed further in the following sections. The H/C ratio and the $\mathrm{C}, \mathrm{H}, \mathrm{N}, \mathrm{S}$ and $\mathrm{O}$ concentrations in the three crude oil samples are shown in Table 1. As shown, sample B has the lowest $\mathrm{H} / \mathrm{C}$ ratio and the highest sulfur and nitrogen contents.

Figure 1 shows the variations in $G^{\prime \prime}$ for the three oil samples as a function of the PAM concentration and temperature. A PAM concentration of $50 \mathrm{ppm}$ results in the highest $G^{\prime \prime}$ values for samples A and B, while for sample C, $70 \mathrm{ppm}$ PAM results in the highest $G^{\prime \prime}$ value. The addition of more PAM results in a decrease in the $G^{\prime \prime}$ value, as seen with $70 \mathrm{ppm}$ for samples A and B, and $100 \mathrm{ppm}$ for sample C. For samples $\mathrm{A}$ and $\mathrm{B}$, the increase in the $G^{\prime \prime}$ value is less than that for sample $\mathrm{C}$, which is caused by a loss in energy due to the larger amount of wax crystals in sample $\mathrm{C}$ collapsing.

The variations in $G^{\prime \prime}$ as a function of frequency and temperature are shown in Fig. 2 for samples A and C. As mentioned above, $G^{\prime \prime}$ represents the amount of energy dissipated when the crystal structure in crude oil collapses. With an increase in temperature, the $G^{\prime \prime}$ values decrease, i.e., more energy is lost as the crystal structure collapses with an increase in temperature. As the frequency increases, the $G^{\prime \prime}$ values for both samples increase. In sample $\mathrm{C}$, the $G^{\prime \prime}$ values taper at frequencies close to $1 \mathrm{~Hz}$. This process may be related to the greater disorder in the wax and the loss of energy due to the collapse of low-molecular weight wax crystals.
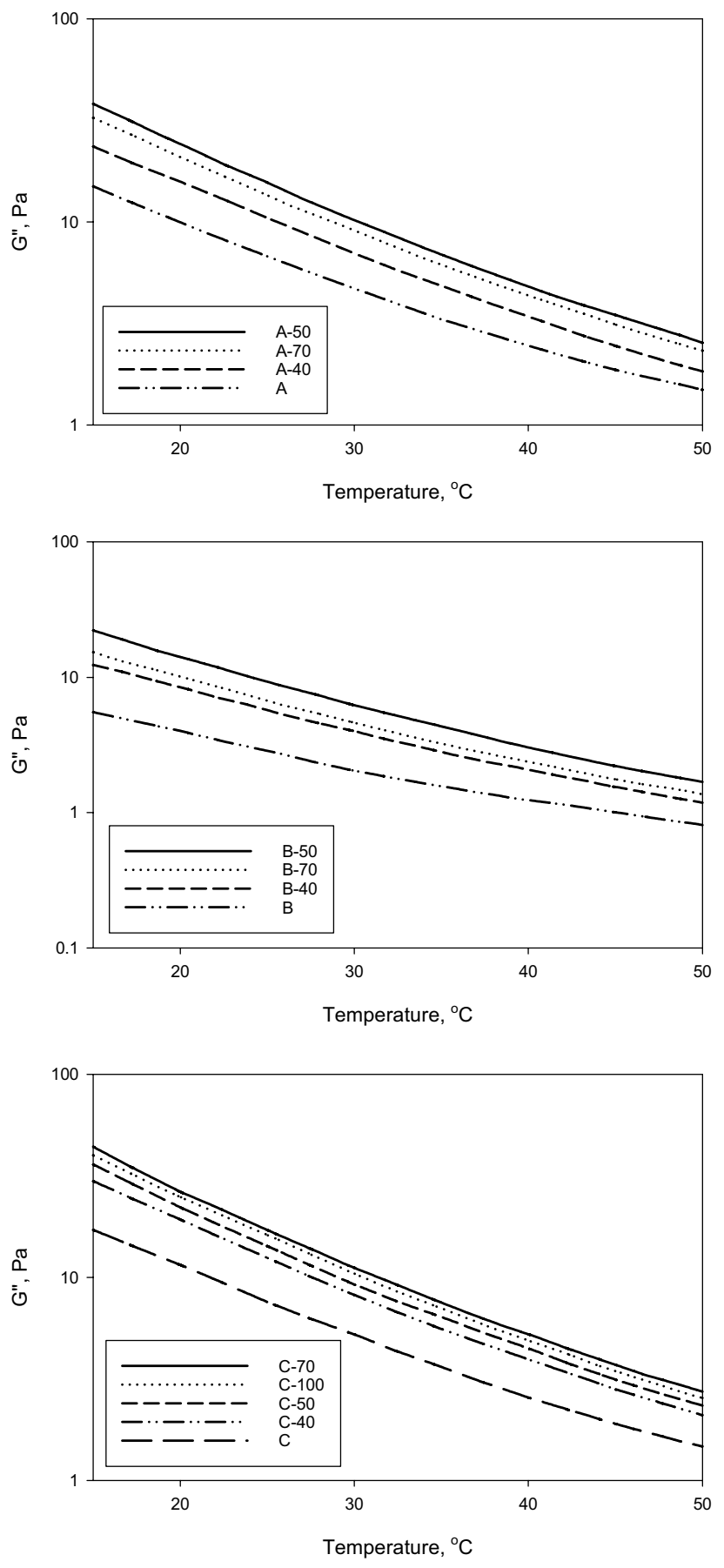

Fig. 1 Variation in the loss modulus $\left(G^{\prime \prime}\right)$ for samples A, B, and C as a function of temperature and PAM concentration

Non-Newtonian characteristics have been exhibited by untreated and treated crude oil samples when studied in the viscometry mode of the rheometer. The oils are found to have a shear thinning nature. Figure 3 shows the variation in viscosity $(\eta)$ as a function of temperature for the three oil samples. As shown, the viscosity decreases in the order of sample $\mathrm{C}>\mathrm{A}>\mathrm{B}$. The decrease in viscosity noted is an 

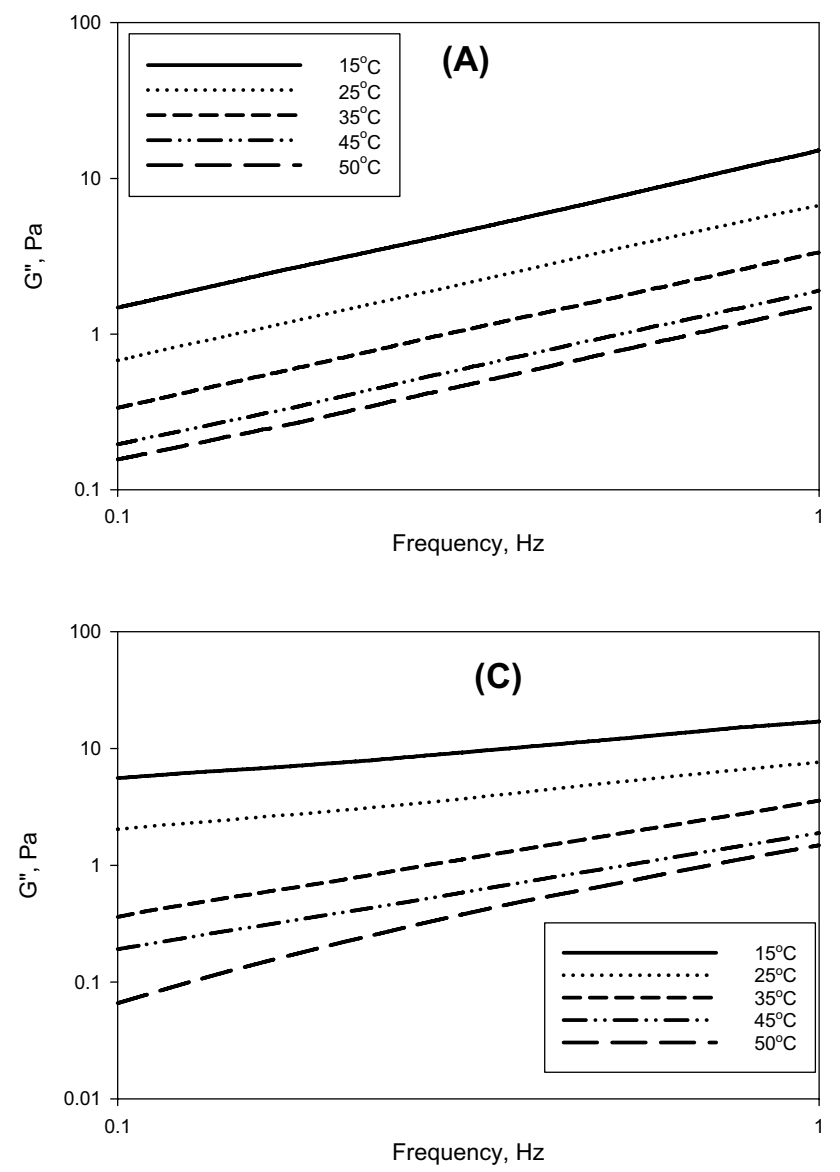

Fig. 2 Variation in the loss modulus $\left(G^{\prime \prime}\right)$ for samples A and $\mathrm{C}$ as a function of frequency and temperature

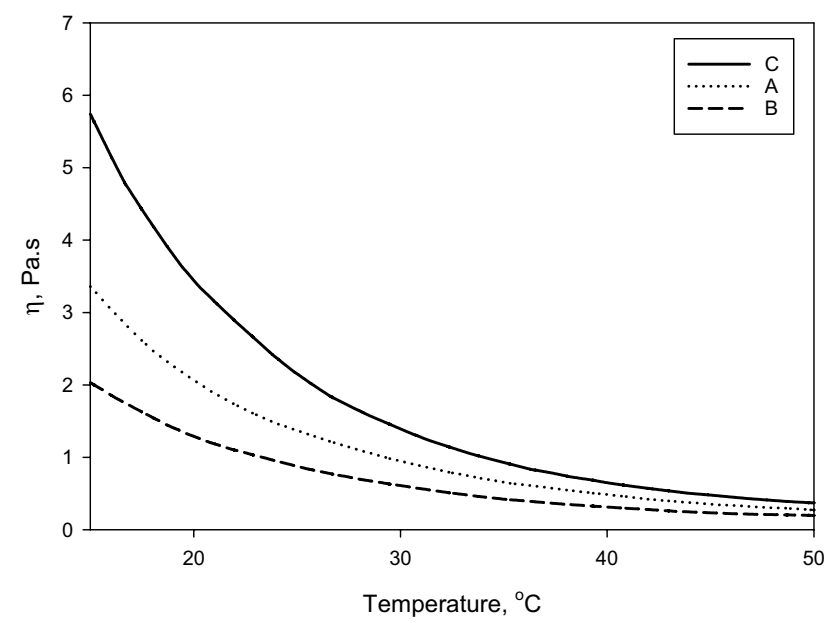

Fig. 3 Variation in viscosity for samples A, B and C as a function of temperature

inherent property of the oils. This observation is consistent with the API values of the crude oil sample (Table 1). The viscosities of the three samples decrease with an increase in temperature. At temperatures above $40{ }^{\circ} \mathrm{C}$, the viscosities of all the samples are similar due to the melting of isoparaffins.

Figure 4 shows the variations in the viscosity of sample $\mathrm{C}$ as a function of temperature and shear stress. As shown, at a constant temperature and increasing stress values, the viscosity decreases. This behavior is caused by a reduction in wax gelation and agglomerate formation rates. Higher viscosities are also obtained at lower temperatures due to increasing agglomerate formation and wax gelation rates. The effect of a higher shear stress on the sample viscosity and wax gelation delay was also reported by Kane et al. (2004).

The viscous behavior of crude oil is due to the presence of hydrogen bonding and overlapping of aromatic rings present between different asphaltene molecules and asphaltene/resin (Soni et al. 2010). The greater the amount of asphaltenes and resins present in the oil is, the higher the viscosity of the crude oil is. To reduce the viscosity of the crude oil, the hydrogen bond between the resin and the asphaltene should be broken. Upon the addition of a surfactant to the crude oil, strong hydrogen bond formation occurs between the surfactant and resin, and the surfactant and asphaltene, reducing the overlapping of aromatic rings between asphaltene-asphaltene and asphaltene-resin molecules. The presence of polar groups in PAM helps to form strong hydrogen bonds between surfactant and resin, and asphaltene molecules, causing it to act as an effective flow improver.

Figure 5 shows the changes in viscosity of sample $\mathrm{C}$ as a function of temperature and PAM concentration. The lowest viscosity curve is obtained with a PAM concentration of $70 \mathrm{ppm}$, and further increases or decreases in the PAM concentration result in an increase in sample viscosity. Thus, 70 ppm PAM is the optimum surfactant concentration and can effectively break wax agglomerates. Georgi et al. (2015)

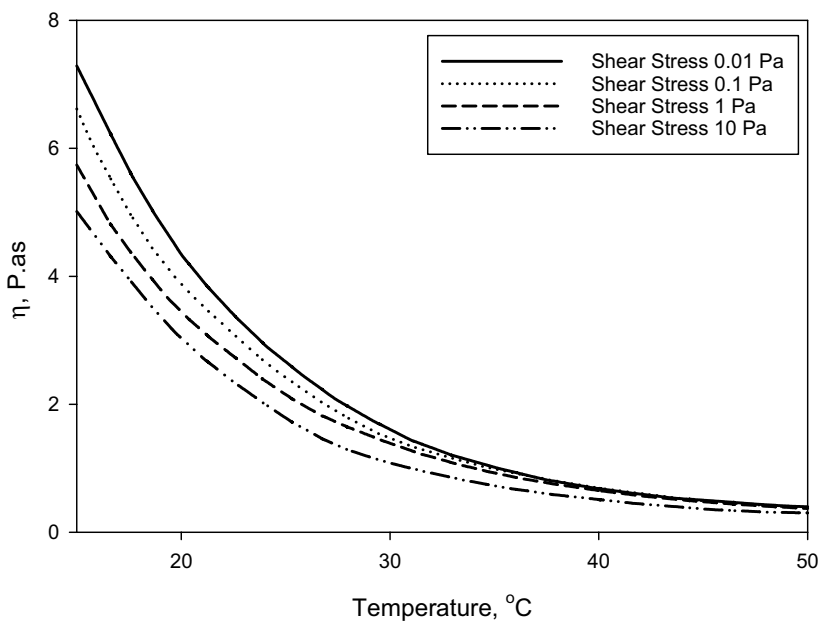

Fig. 4 Variation in viscosity for sample $\mathrm{C}$ as a function of temperature and shear stress 


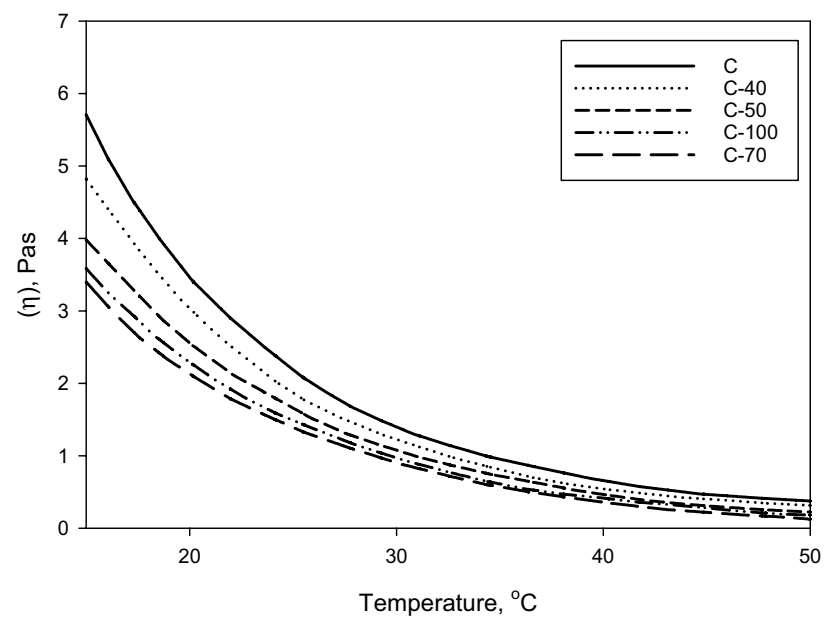

Fig. 5 Variation in viscosity for sample $\mathrm{C}$ as a function of temperature and PAM concentration

reported a similar observation when studying changes in drag reduction characteristics as a function of the concentration of poly-1-octene dissolved in heptane. They observed that the drag reduction increased to a maximum of $63 \%$ at a surfactant concentration of $2.5 \mathrm{ppm}$ and decreased to $58 \%$ when the surfactant concentration increased to $4.5 \mathrm{ppm}$.

The variations in viscosities of sample A, B and C as a function of temperature are shown in Fig. 6. The linear portion of the curve for each sample is used to obtain the Arrhenius relationship and the corresponding activation energy, which are shown as numeric values. The deviation from the Arrhenius relationship indicates non-Newtonian flow characteristics due to wax formation and gelation.

Figure 7 shows the variations in sample strain as a function of the frequency. The sample strain is the deformation that occurs upon the application of a defined amount of force

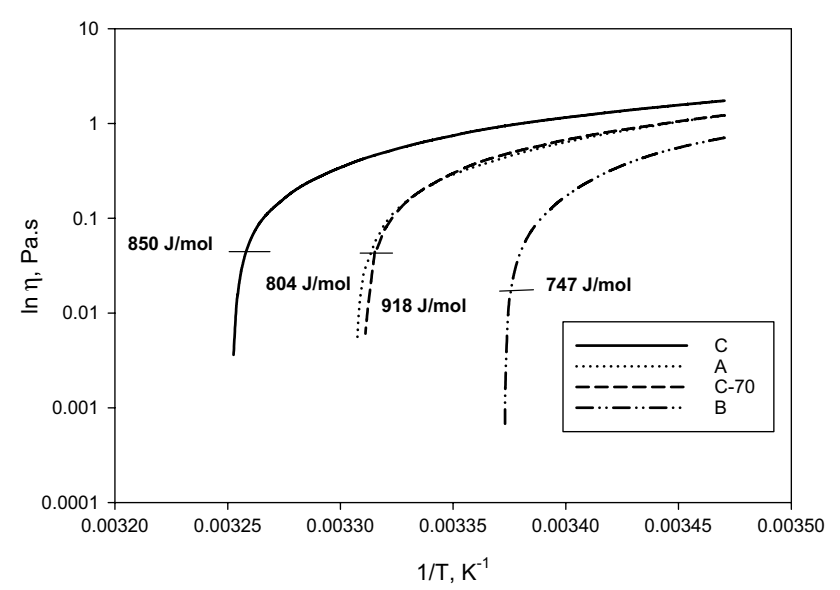

Fig. 6 Arrhenius plots of viscosity and temperature for samples A, B, $\mathrm{C}$ and $\mathrm{C}-70$ and is a dimensionless quantity. The strain values decrease in the order of $\mathrm{B}>\mathrm{A}>\mathrm{C}-70>\mathrm{C}$. Low API values are indicative of more waxy components in crude oil. Sample $\mathrm{C}$ has the lowest API value, and its deformation is lower than that of samples B and A. The deformation of sample C-70 is greater than that of sample $\mathrm{C}$, indicating the breakdown of waxy compounds in the neat sample.

Figure 8 shows the variations in viscosities of sample A and $\mathrm{B}$ as a function of the shear stress, and the surfactant PSSS concentration for sample A and the surfactant CHP concentration for sample B. At temperatures below $30{ }^{\circ} \mathrm{C}$, the simultaneous increase in shear stress to $1 \mathrm{~Pa}$ and the addition of $70 \mathrm{ppm}$ surfactants drastically reduce the viscosity of both samples. Further data on this behavior are shown in Fig. 9 for the variations in the viscosities of samples $\mathrm{A}$ and $\mathrm{B}$ at a shear stress of $1 \mathrm{~Pa}$, cooling rate of $1^{\circ} \mathrm{C} / \mathrm{min}$, and 70 ppm surfactant. At temperatures below $30^{\circ} \mathrm{C}$, SDS has no effect on the viscosity of sample A. However, the other surfactants, CHP, CTAB, HTPC, and PSSS, had a similar effect and drastically reduced the viscosity of sample (A). For sample B, CHP has a distinguishable effect, and CTAB most effectively reduces the viscosity of sample (B) Additionally, HTPC, PSSS, and SDS have adverse effects on the sample viscosity, and the measured viscosity is higher than that of the pure sample.

The variation in the viscosities of the crude oil samples A and $\mathrm{B}$ as a function of the surfactant concentration at $30^{\circ} \mathrm{C}$ is shown in Fig. 10. The results show that at a concentration of 70 ppm, PSSS is a suitable surfactant for crude oil sample A, while CHP is a suitable surfactant for crude oil sample B.

Figure 11 shows the variation in the viscosities of samples A and B as a function of the temperature and the surfactant concentration. The addition of PSSS to sample A substantially reduces the viscosity, especially at temperatures below $30^{\circ} \mathrm{C}$. However, a further increase in PSSS

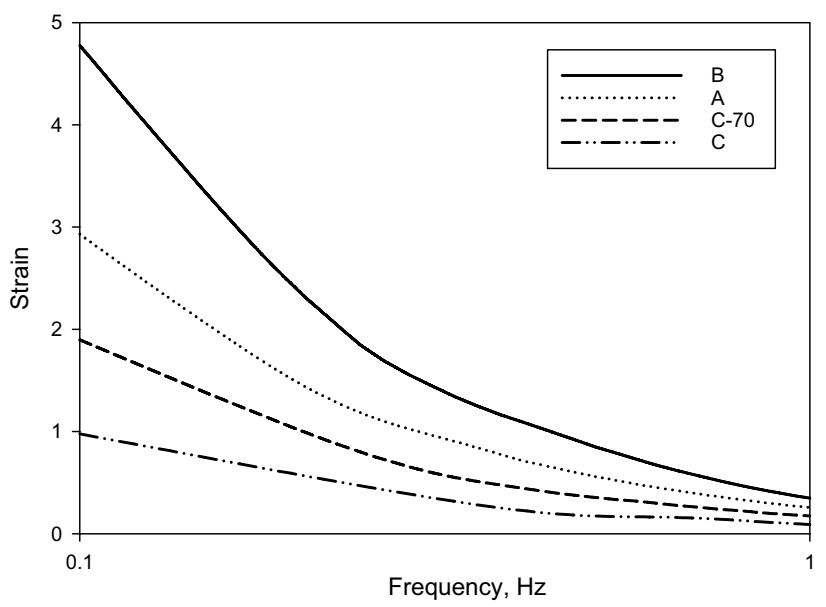

Fig. 7 Variations in strain for samples A, B and C as a function of frequency 

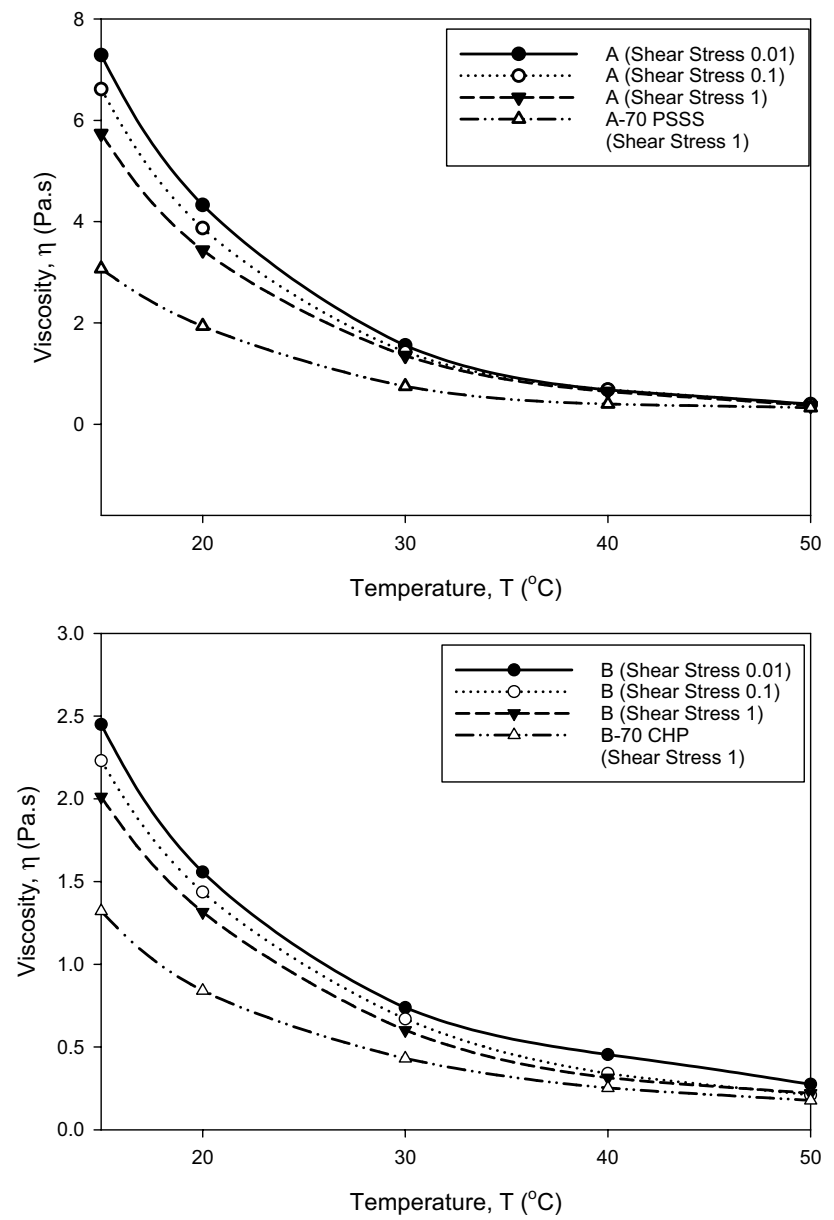

Fig. 8 Variations in viscosity for samples A and B as a function of temperature and shear stress

concentration has a limited effect on the further viscosity reduction. However, CHP reduces the viscosity of sample $B$ with an increase in surfactant concentration from 40 to $70 \mathrm{ppm}$. CHP contains an equimolar ratio of a cationic surfactant (CTAB), anionic surfactant (PSSS) and zwitterionic surfactant (HTPC), which collectively have the ability to break down wax crystal agglomerates due to the combined effect of the surfactants. The maximum CHP concentration required to further reduce the drag of crude oil sample B was not determined, and this will be probed in future work.

To verify the consistency of the measurements, the percentage differences were obtained as follows:

$\%$ diff. $=\frac{\mu_{1}-\mu_{2}}{\frac{\mu_{1}+\mu_{2}}{2}} \times 100$.

In the above equation, $\mu_{1}$ is the viscosity of the crude oil from the first run and $\mu 2$ is the viscosity from the second run. An average percentage difference of three different runs
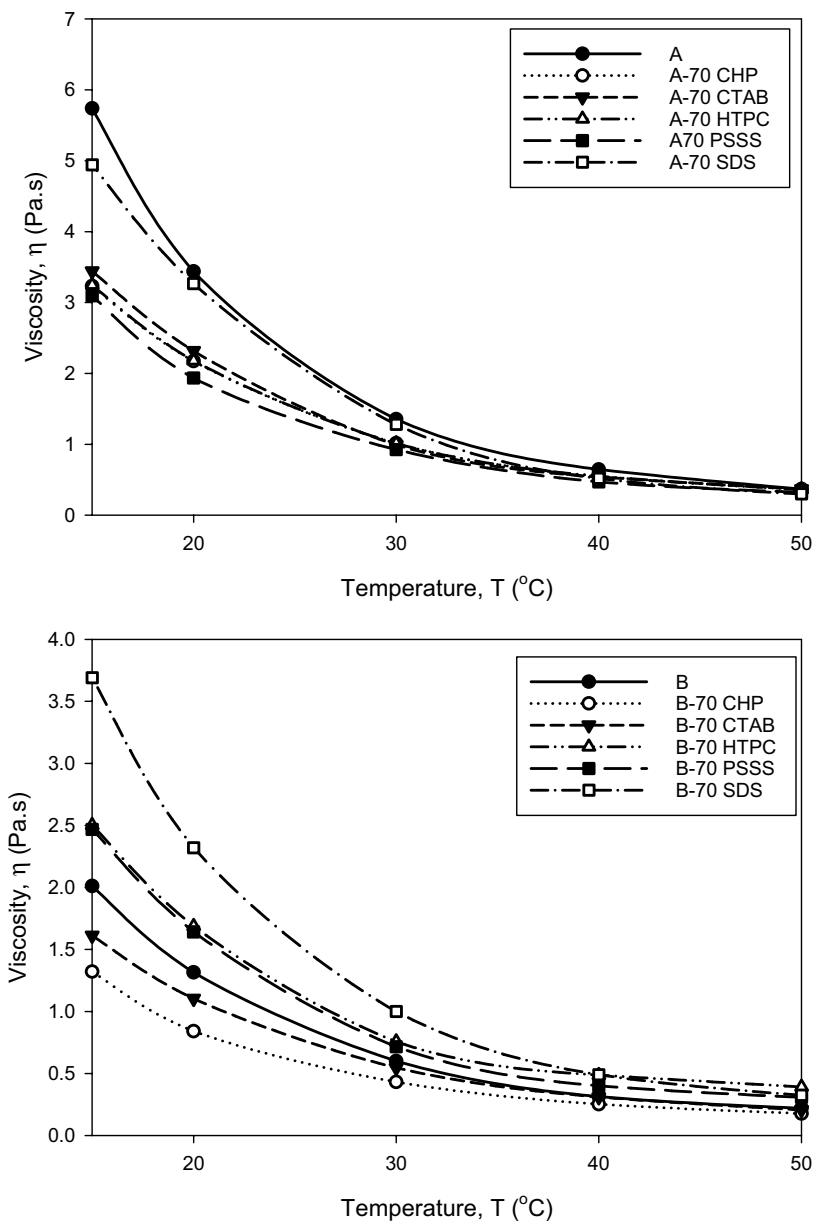

Fig. 9 Variations in viscosity for samples A and B as a function of temperature and type of surfactant

from three different combinations was obtained and the percentage difference was found to be less than $5 \%$.

Figure 12 shows the variation in $G^{\prime \prime}$ as function of the temperature and the surfactant concentration for samples A and B. For the heavy crude oil sample A with a low API value, PSSS results in the lowest energy dissipation under shear, while CHP results in the lowest $G^{\prime \prime}$ value for sample $\mathrm{B}$, which has a high API value. These results may be due to the formation of high-viscosity emulsions of surfactants with other compounds present in the crude oil (Ashrafizadeh et al. 2012). The differences in the viscosities of the pure samples and the surfactant-treated samples at low temperatures are more pronounced for sample B than for sample A, which may be due to the collapse of more crystals in the lighter crude sample.

Figure 13 shows the variation in the loss modulus $\left(G^{\prime \prime}\right)$ as a function of the temperature at a cooling rate of $1{ }^{\circ} \mathrm{C} / \mathrm{min}$ and a constant shear stress of $1 \mathrm{~Pa}$. $G^{\prime \prime}$ represents the energy that dissipates during the viscous flow of a material. The neat crude oil has the least amount of energy that dissipates 

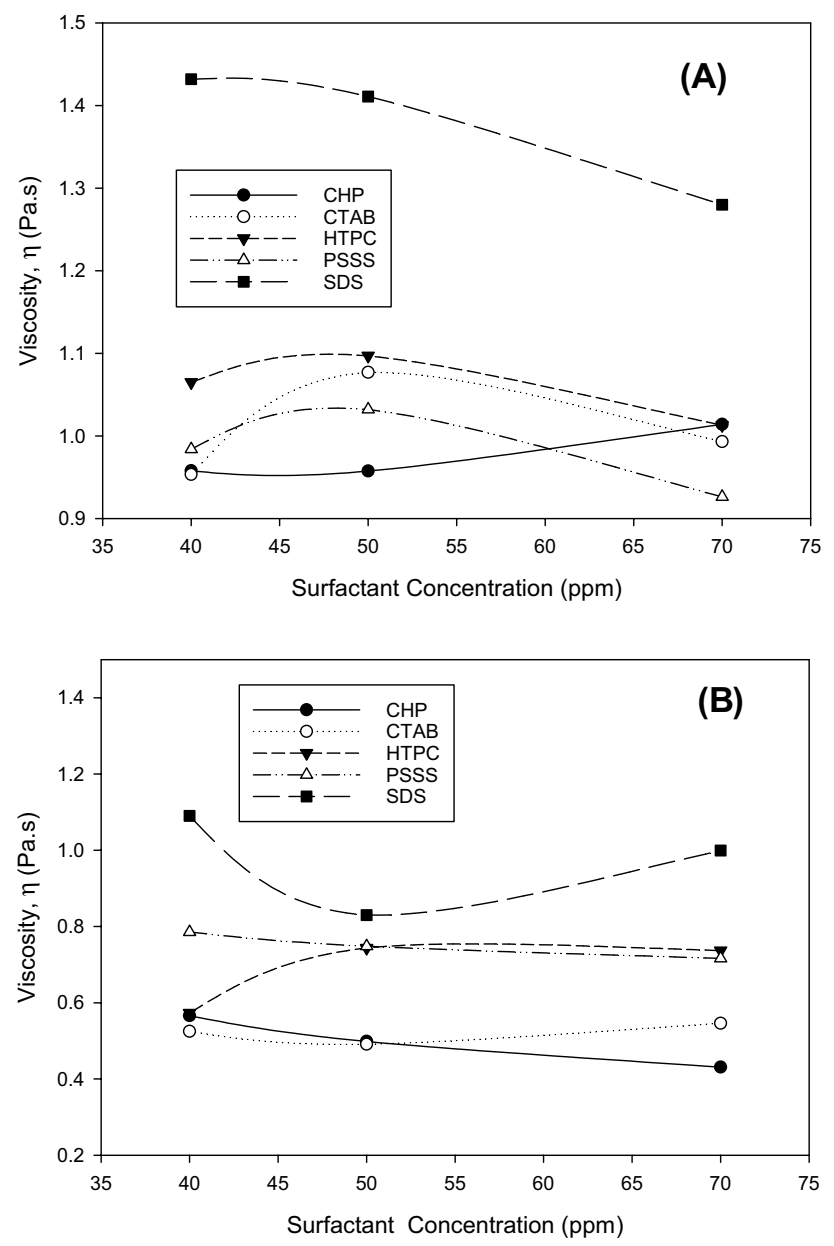

Fig. 10 Variation in viscosity as a function of surfactant concentration for samples A and B

during the flow and is followed by the crude oil containing 70 ppm surfactants. The higher $G^{\prime \prime}$ value of the crude oil containing surfactants may be due to the formation of highviscosity emulsions (Ashrafizadeh et al. 2012). As the PSSS and CHP concentrations in the raw crude oil increase, the energy dissipation also increases. However, as the temperature decreases, the difference between the $G^{\prime \prime}$ value of the raw crude and that of the surfactant-treated crude increases. Sample B has lower $G^{\prime \prime}$ values than sample A, indicating sample B loses less energy during shearing.

\section{Conclusion}

The present work is a nonisothermal evaluation of the rheological characteristics of three Kuwaiti crude oil samples obtained from different locations in Kuwait with different API values. The $G^{\prime \prime}$ values were the highest for the low-API crude oil, sample C. The $G^{\prime \prime}$ values increased as the temperature decreased. This behavior was not observed with
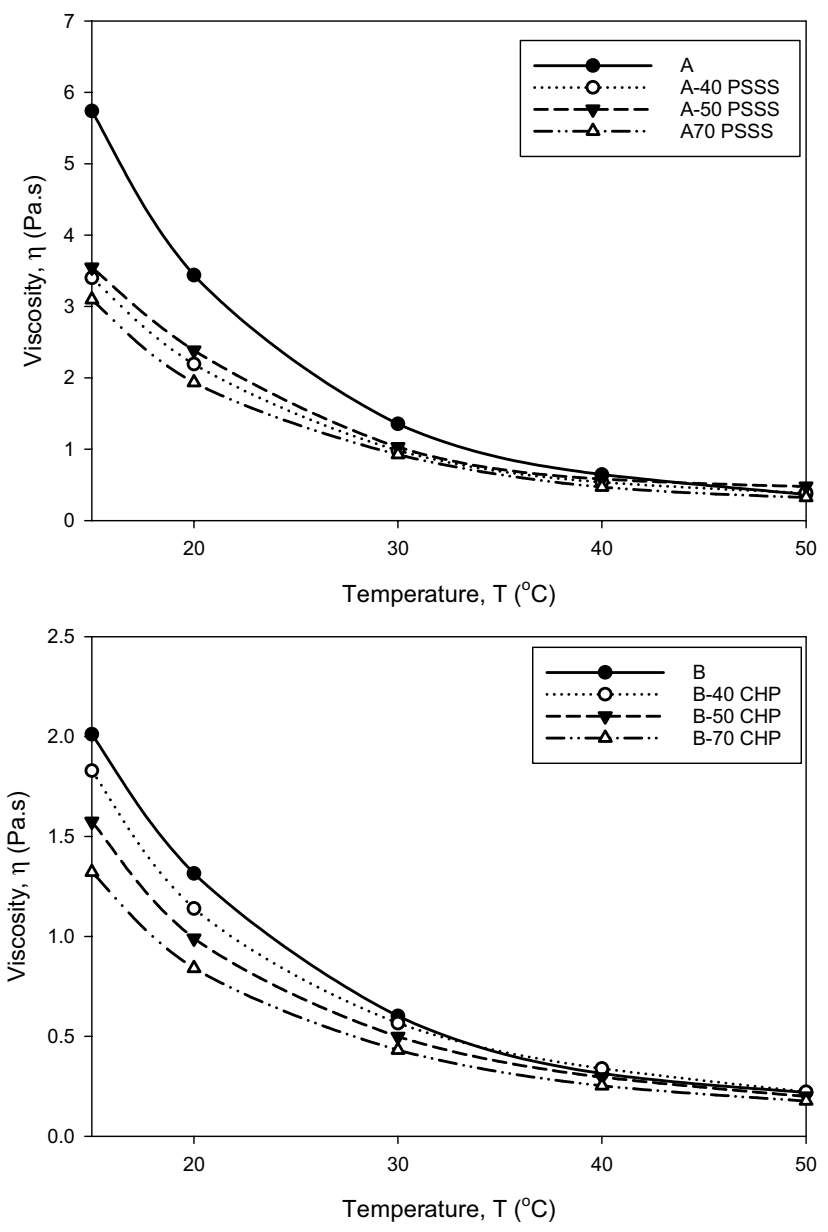

Fig. 11 Variations in viscosity for samples A and B as a function of temperature and surfactant concentration

decreasing frequency values, but the lowest temperature results in the maximum $G^{\prime \prime}$ value for all the samples. Different concentrations $(40,50,70$ and $100 \mathrm{ppm})$ of PAM, the DRA, were used for neat crude oil samples A, B and C. A concentration of $70 \mathrm{ppm}$ PAM decreased the viscosity of the treated crude oil samples compared with that of the neat samples. At a constant stress and temperature value below $40{ }^{\circ} \mathrm{C}$, the viscosity followed the trend of sample $\mathrm{C}>\mathrm{A}>\mathrm{B}$, and the differences in viscosity values increased below $20^{\circ} \mathrm{C}$. A study on the effect of the variations in shear stress on the viscosity as a function of temperature indicated that low shear stress values lead to the formation of more waxy agglomerates. The Arrhenius plots revealed that the addition of $70 \mathrm{ppm}$ PAM to the neat crude oil decreased the temperature required to break down the waxy structures present in the crude oil.

Different surfactants, including CTAB (cationic), PSSS, SDS (anionic) and HTPC (zwitterionic), at a molar ratio of 1:1:1 of CTAB:HTPC:PSSS, were used as DRAs. Nonisothermal rheometric studies were conducted in aqueous 

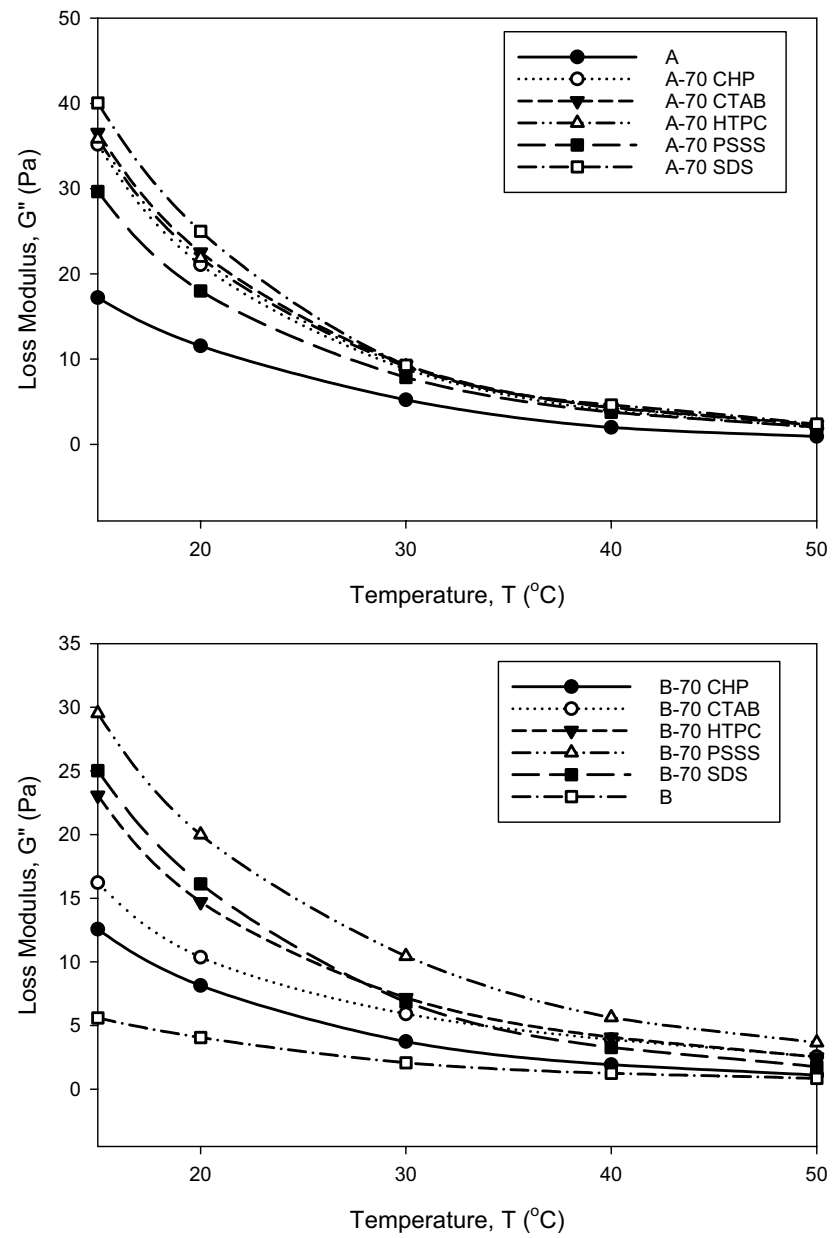

Fig. 12 Variation in the loss modulus $\left(G^{\prime \prime}\right)$ as a function of temperature for different surfactants at a concentration of $70 \mathrm{ppm}$ in sample A and sample B

solutions with 40, 50 and 70 ppm DRAs. The viscometric analysis revealed that the lowest viscosity for crude A was with 70 ppm PSSS, while the lowest viscosity value for crude B was with 70 ppm CHP.

The plot of $G^{\prime \prime}$ versus temperature showed that the neat crude (both A and B) oil samples had the lowest viscous modulus values, followed by the crude oil containing 70 ppm PSSS and CHP. The higher values of $G^{\prime \prime}$ may be due to the formation of viscous emulsions with larger viscous modulus values.

Acknowledgements The authors would like to thank the Research Administration of Kuwait University for providing funds for project RE $05 / 14$ to carry out this research. The authors would like to thank Dr. Johnson Mathew, Denie Yohannan and Joyson John for data interpretation and technical support during the execution of the project. The authors are grateful for the Petroleum Refining and Petrochemical Research Centre (PRPC-GE 03/08) of the Research Administration of Kuwait University for carrying out the elemental analysis.
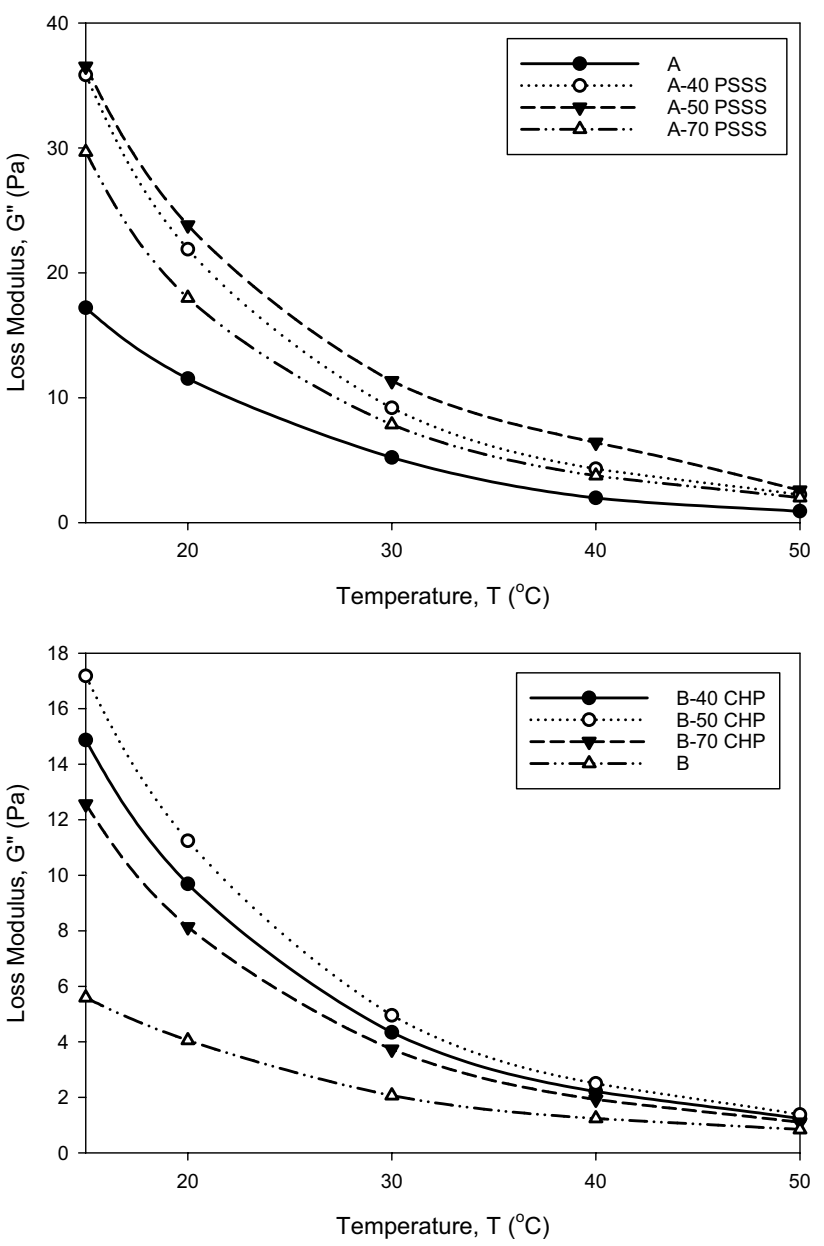

Fig. 13 Plot of loss modulus $\left(G^{\prime \prime}\right)$ as a function of temperature for different concentrations of the best surfactant for sample A and sample B

Open Access This article is distributed under the terms of the Creative Commons Attribution 4.0 International License (http://creativeco mmons.org/licenses/by/4.0/), which permits unrestricted use, distribution, and reproduction in any medium, provided you give appropriate credit to the original author(s) and the source, provide a link to the Creative Commons license, and indicate if changes were made.

\section{References}

Abdul-Hadi AA, Khadom AA (2013) Studying the effect of some surfactants on drag reduction of crude oil flow. Chin J Eng. https:// doi.org/10.1155/2013/321908

Albusairi BH, Al-Mulla A (2017) A study of flow properties of Kuwaiti crude oil obtained from different sources. J Pet Sci Tech 7:79-90

Al-Roomi Y, George R, Elgibaly A, Elkamel A (2004) Use of a novel surfactant for improving the transportability/transportation of heavy/viscous crude oils. J Petrol Sci Eng 42:235-243

Angstadt HP, Tsao H (1987) Kinetic Study of the Decomposition of Surfactants for EOR, SPE, Sun Co. Inc. H. Tsao, Sun Co. Inc. SPE Reservoir Engineering 
Ashrafizadeh SN, Motaee E, Hoshyargar V (2012) Emulsification of heavy crude oil in water by natural surfactants. J Pet Sci Eng 86-87:137-143

Bewersdorff HW, Ohlendorf D (1988) The behavior of drag reducing cationic surfactant solutions. Colloid Polym Sci 226:941-953

Chang C, Boger DV, Nguyen QD (1998) The yielding of waxy crude oils. Ind Eng Chem Res 37:1551-1559

Chang C, Nguyen QD, Ronningsen HP (1999) Isothermal start-up of pipeline transporting waxy crude oil. J Non-Newtonian Fluid Mech 87:127-154

Dirand M, Chevallier V, Provost E, Bouroukba M, Petitjean D (1988) Multicomponent paraffin waxes and petroleum solid deposits: structural and thermodynamic state. Fuel 77:1253-1260

Gad-el-Hak M (2006) Flow control: passive, active, and reactive flow management. Cambridge University Press, Cambridge

Georgi VN, Konovalov KB, Vetrovad OV, Menshov P (2015) Laboratory evaluation of the drag reduction additives effectiveness. Procedia Chem 15:371-377

Hadri F, Guillou S (2010) Drag reduction by surfactant in closed turbulent flow. Int J Eng Sci Tech 2:6876-6879

Handy LL, Amaefule JO, Ziegler VM, Ershaghi I (1979) Thermal stability of surfactants for reservoir application, SPE 7867, presented at the SPE of AIME International Symposium on Oilfield and Geothermal Chemistry, Houston, Texas, Jan. 22-24, 1979

Hannisdal A, Hemmingsen PV, Sjoblom J (2005) Group-type analysis of heavy crude oils using vibrational spectroscopy in combination with multivariate analysis. Ind Eng Chem Res 44:1349-1357

Hassanean MH, Awad ME, Marwan H, Bhran AA, Kaoud M (2016) Studying the rheological properties and the influence of drag reduction on a waxy crude oil in pipeline flow. Egypt $J$ Pet 25:39-44

Hellsten M, Harwigsson I (1996) Use of a betaine surfactant together with an anionic surfactant as a drag-reducing agent. Patent No. WO/1996/028527

Kane M, Djabourrov M, Volle JL (2004) Rheology and structure of waxy crude oils in quiescent and under shearing. conditions Fuel 83:1591-1605

Morgan SE, McCormick CL (1990) Water-soluble copolymers XXXII: macromolecular drag reduction. A review of predictive theories and the effects of polymer structure. Prog Polym Sci 15:507-549

Mowla D, Naderi A (2006) Experimental study of drag reduction by a polymeric additive in slug two-phase flow of crude oil and air in horizontal pipes. Chem Eng Sci 61:1549-1554

Mozaffari S, Tchoukov P, Atias J, Czarnecki J, Nazemifard N (2015) Effect of asphaltene aggregation on rheological properties of diluted athabasca bitumen. Energy Fuels 29:5595-5599

Mozaffari S, Tchoukov P, Mozaffari A, Atias J, Czarneckia J, Nazemifard N (2017) Capillary driven flow in nanochannels-application to heavy oil rheology studies. Coll Surf A: Physicochem Eng Aspects 513:178-187

Myers D (2006) Surfactant science and technology, 3rd edn. Wiley, Hoboken, NJ

Pedersen WB, Hansen AB, Larsen E, Nielsen AB, Roenningsen HP (1991) Wax precipitation from North Sea crude oils. 2. Solidphase content as function of temperature determined by pulsed NMR. Energy Fuel 5:908-913

Popoola CA, Ayo JA, Adedeji OE, Akinleye O (2015) Triethanolamine (TEA) as flow improver for heavy crude oils. J Appl Chem $8: 34-38$
Ptasinski PK, Nieuwstadt FTM, van den Brule BHAA, Hulsen MA (2001) Experiments in turbulent pipe flow with polymer additives at maximum drag reduction. Flow Turbul Combust 66:159-182

Rafael M, Guillaume V, Guillaume O, Philippe C (2015) Modeling the rheological behavior of waxy crude oils as a function of flow and temperature history. J Rheol 59:703-732

Remelisa, Esteves, Nonso Onukwuba and Birce Dikici (2016) Determination of surfactant solution viscosities with a rotational viscometer, embry-riddle, aeronautical university, Beyond under graduate research journal

Robertson RE (1957) Reactions of Sulfonic Esters: V1. The temperature dependence of the rate for the hydrolysis of a series of alkyl benzene sulfonates. Cdn 1 Chern 35:613-621

Ronningsen HP (1992) Rheological behavior of gelled, waxy North Sea crude oils. J Pet Sci Eng 7:177-213

Russell RJ, Chapman ED (1971) The pumping of $85 \mathrm{~F}$ pour point Assam (Nahorkatiya) crude oil at 65 F. J Inst Pet 57:117-128

Singh RP (2004) Drag reduction. encyclopedia of polymer science and technology. Wiley

Singh P, Fogler HS, Nagarajan N (1999) Prediction of the wax content of the incipient wax-oil gel in a pipeline: an application of the controlled-stress rheometer. J Rheol 43:1437-1459

Singh P, Venkatesan R, Fogler HS, Nagarajan N (2004) Formation and aging of incipient thin film wax-oil gels. AIChE J 46:1059-1074

Soni HP, Bharambe DP (2006) Synthesis and evaluation of polymeric additives as flow improvers for Indian crude oil. Iran Polym J 15:943-954

Soni H, Kiranbala P, Agrawal KS, Nagar A, Bharambe DP (2010) Designing maleic anhydride- $\alpha$-olifin copolymeric combs as wax crystal growth nucleators. Fuel Proc Tech 91:997-1004

Stelter M, Brenn G (2000) Validation and application of a novel elongational device for polymer solutions. J Rheol 44:595-616

Toonder D, Hulsen JJ, Kuiln GC, Nieuwstadt FM (1997) Drag reduction by polymer additives in a turbulent pipe flow: numerical and laboratory experiments. J Fluid Mech 337:193-231

Usui H, Saeki T (1993) Drag-reduction and heat transfer reduction by cationic surfactants. J Chem Eng Jpn 26:103-106

Wardhaugh LT, Boger DV (1991a) Flow characteristics of waxy crude oils: application to pipeline design. AIChE J 37:871-885

Wardhaugh LT, Boger DV (1991b) The measurement and description of the yielding behavior of waxy crude oil. J Rheo 35:1121-1156

Wunderlich T, Stelter M, Tripathy T, Nayak BR, Brenn G, Tarin AL, Durst F (2000) Shear and extensional rheological investigations in solutions of grafted and ungrafted polysaccharides. J Appl Polym Sci 77:3200-3209

Zakin JL, Lu B, Bewersdorff HW (1998) Surfactant drag reduction. Rev Chem Eng 14:252-320

Zirnsak MA, Boger DV, Tirtaatmadja V (1999) Steady shear and dynamic rheological properties of xanthan gum solutions in viscous solvents. J Rheol 43:627-650

Publisher's Note Springer Nature remains neutral with regard to jurisdictional claims in published maps and institutional affiliations. 